\title{
Ayurvedic Management of Acute Food Induced Anaphylactic Reaction - A Case Report
}

\begin{abstract}
Some foods are known to cause toxic effects and adverse reactions in some individuals. The list of foods implicated in anaphylactic reactions is unlimited and any food protein is capable of causing an anaphylactic reactions. Food anaphylaxis is an allergic syndrome manifested by an abrupt onset of symptoms within minutes to hours after ingesting a food. Anaphylaxis is recognized by cutaneous, respiratory, cardiovascular and gastrointestinal signs and symptoms occurring singly or in combination. The only proven therapy for food induced allergic reactions is the strict elimination of the suspected food or allergen. It is very difficult to follow strict elimination especially in India where prepared food is a complex mixture. Studies on food allergy are still in infancy in India. Studies are lacking in the prevention and management of acute food induced anaphylactic reactions with Ayurveda. Various allergic conditions can be correlated with 'Sheeta pitta', 'Udarda' and 'Kotha' etc diseases explained in Ayurvedic texts. The present case report deals with a patient of acute food induced anaphylactic reaction managed by Ayurvedic drugs. Sanjeevani gutika and Haridra khanda at the initial/early stages of food induced anaphylactic reaction seems to be beneficial in preventing anaphylactic shock or further aggravation of condition. These Ayurvedic drugs seem to be promising in the emergency management of acute food induced allergic reactions.
\end{abstract}

Keywords: Food allergy; Ayurveda; Anaphylactic reaction; Anaphylactic shock; Sanjeevani gutika, Haridra khanda

Case Report
Volume 10 Issue 3 - 2017
Kshama Gupta* and Prasad Mamidi
Department of Kayachikitsa, Parul Institute of Ayurved, Parul
University, India
*Corresponding author: Prasad Mamidi, Dept of
Kayachikitsa, Faculty of Ayurveda, Parul University,
Vadodara, Gujarat, 391760, India, Tel: 7567222856,
Email: drprasadmamidi@gmail.com
Received: November 10, 2016 | Published: December 29,
2017

Abbreviations: AEC: Absolute Eosinophil Count; ESR: Erythrocyte Sedimentation Rate; HDL High Density Lipoprotein; IgE: Immunoglobulin E; DBPCFI: Double Blind Placebo Controlled Food Index; FEV: Forced Expiratory Volume

\section{Introduction}

Food anaphylaxis is an allergic syndrome manifested by an abrupt onset of symptoms within minutes to hours after ingesting a food. Anaphylaxis is recognized by cutaneous, respiratory, cardiovascular and gastrointestinal signs and symptoms occurring singly or in combination. The list of foods implicated in anaphylactic reactions is unlimited and any food protein is capable of causing an anaphylactic reaction [1]. Some foods are known to cause toxic effects and adverse reactions in some individuals. Adverse food reactions can be defined as abnormal responses to an ingested food. The abnormal food reactions could be either due to food hypersensitivity, food allergy or food intolerance. Food allergies are the single most common cause of generalized anaphylaxis in hospital emergency departments accounting for about one third of cases. Studies on food allergy are still in infancy in India. Although food induced allergic reactions to be quite high, very few significant data is published to address this issue in India [2].

The only proven therapy for food induced allergic reactions is the strict elimination of the suspected food/allergen. It is very difficult to follow strict elimination especially in India where prepared food is a complex mixture. Avoidance is easier said than done and as hidden allergens pose a possible fatal risk, the patients should be provided with an emergency plan for medication and actions to be taken when accidental ingestion occurs [3]. Studies are lacking in the prevention and management of acute food induced anaphylactic reactions with Ayurvedic medicines. Various allergic conditions can be correlated with 'Sheeta pitta', 'Udarda' and 'Kotha' etc diseases explained in Ayurvedic texts [4]. The present case report deals with a patient of acute food induced anaphylactic reactions came for Ayurvedic treatment. Written informed consent was obtained from the patient for the publication of this case report and accompanying images.

\section{Case Description}

A 38 year old male patient came to our care (19.09.2016) with the complaints of pruritis, flushing, generalized urticaria, edema and pruritis of lips, pilor erecti, feeling of faintness and lightheadedness which have started after ingesting breakfast dish (which contains semolina, yogurt and coconut). The patient has been suffering with such type of allergic reactions since 2009. The patient has developed anaphylactic shock eight times previously and managed by intravenous anti histamines and corticosteroids at emergency department. The anaphylactic reactions have occurred most of the times after ingesting a wide variety of food items like, semolina, wheat (cooked) with lemon, pickles (which contains coloring agents or preservatives), Chinese food items like Noodles and Manchurian and curries (which contains food coloring agents). Each time the food item is different and severity 
of reaction was also different (ranging from mild, self limiting generalized urticaria to severe anaphylactic shock which needs emergency management). Most of the times the patient has developed allergic reactions after dining out, after ingesting foods which contains artificial food coloring agents and preservatives. Patient has been exposed several times with suspected food item without having allergic reaction also. The patient was unable to trace out a particular food item/molecule/protein exactly which has been producing allergic reactions, as he used to consume foods which are complex mixture containing various ingredients with different methods of preparation.

The allergic reaction starts after half an hour of ingesting suspected food item and gradually proceeds to anaphylactic shock sometimes and resolves automatically without any intervention some other times. Allergic reaction starts with generalized urticaria including pruritis and edema of lips. The urticaria is associated with rash/flushing and pilor erecti which gradually leads to lightheadedness, faintness, hypotension and anaphylactic shock if untreated. The patient used to carry anti histamines and corticosteroid injections along with him always. Patient was non smoker, non alcoholic and not suffering with any other disease. No positive family history found regarding atopy, urticaria, asthma, allergic rhinitis, food allergy or any other relevant allergic condition in family members. Patient has not been taking any medication for allergy on regular basis. Patient has opted for Ayurvedic treatment and came to our care for the management of acute food induced allergic reaction.

At the time of examination, patient had severe pruritis all over the body (Figure 1) including lips. Patient was conscious and able to answer to questions. A complete physical examination was unremarkable except hypotension (blood pressure was 100/60 $\mathrm{mm}$ of $\mathrm{Hg}$ ). Patient also had the feeling of lightheadedness and fainting. Tightness in the throat, dyspnoea, rhinorrhoea, angio-edema, nausea and vomiting were absent. Patient came at the initial stages of anaphylactic reaction and immediately Ayurvedic medicines have been given (patient has preferred Ayurvedic medicines even though antihistamines, corticosteroid injections etc are available at that time). After the administration of Ayurvedic medicines, the anaphylactic reaction has resolved completely within one hour. After few days of the anaphylactic reaction, routine hematological, biochemical investigations, renal function tests and liver function tests were carried out and they all are found within normal limits. AEC (Absolute eosinophil count) was 3000 / cu mm. Erythrocyte sedimentation rate (ESR) was 15 $\mathrm{mm}$ in one hour. Serum cholesterol was $266 \mathrm{mg} / \mathrm{dl}$, serum LDL (low density lipoprotein) was $191 \mathrm{mg} / \mathrm{dl}$, cholesterol / HDL (high density lipoprotein) ratio was 5.61 and serum LDL / serum HDL cholesterol ratio was 4.02, all of which indicates dyslipidaemia (22.09.2016). Skin prick testing and Serum IgE (immunoglobulin E) testing were not conducted.

\section{Diagnosis, Assessment \& Treatment}

The diagnosis of food allergy requires very careful recording of the history of patient's symptoms and food habits, selective skin prick or intra dermal test. The criteria of positive diagnosis by double blind placebo controlled food index (DBPCFI) should be assessed by objective measures such as forced expiratory volume (FEV1) and symptoms score. Diagnosis of food allergy is a complicated process. The presence of foods specific IgE in serum or a positive skin prick test does not always correlate with food allergy for many reasons [2]. Positive testing alone by skin or blood testing, however, does not confirm food allergy as neither mode of testing has a high predictive value. Though skin testing is quite sensitive, it is not very specific [3]. Diagnosis of anaphylactic reaction is made clinically based on history and clinical findings in present case. Skin prick test and IgE testing are not conducted in present case due to non availability and also non affordability of these tests. Patient was diagnosed as having 'food induced anaphylactic reaction' based on history and clinical findings. According to Ayurveda, diagnosis of 'Shettapitta / Udarda / Kotha' (these three conditions used synonymously even though there are slight differences between them) [4] is made.

No assessments were carried out as the patient came in emergency condition and discharged on the same day after the condition gets resolved. The main objective of the treatment was, to manage the anaphylactic reaction and prevent anaphylactic shock with Ayurvedic medication. 'Sanjeevani gutika' (one gram) and 'Haridra khanda' (ten grams) (Figure 2) were prescribed immediately to manage the anaphylactic reaction. The anaphylactic reaction has subsided within an hour after administering these two drugs. Patient was discharged on the same day. Sanjeevani gutika (250 mg twice a day, with water) and Haridra khanda (5 gm with honey, twice a day) were prescribed along with strict diet plan (complete avoidance of suspected food items and also dining out) at the time of discharge.

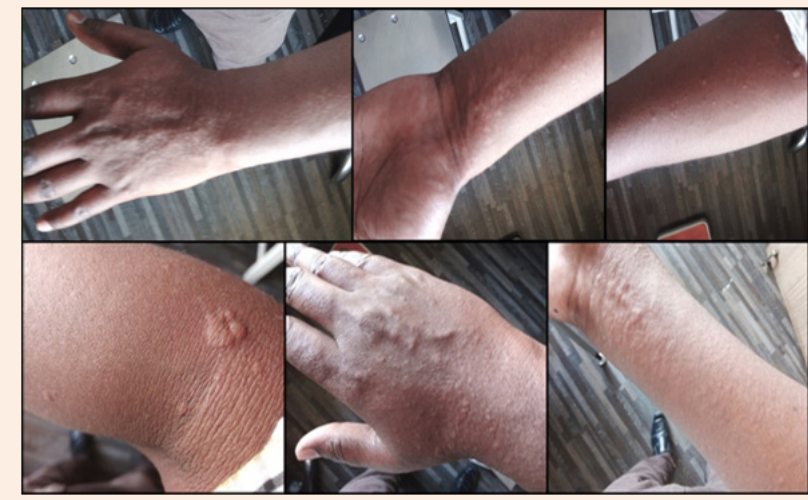

Figure 1: Generalized urticaria of both hands during the initial stages of anaphylactic shock.

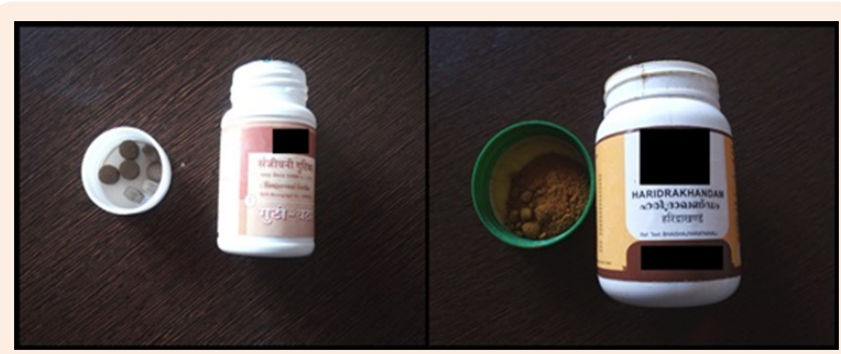

Figure 2: Sanjeevani gutika (Left) \& Haridra khanda (Right). 


\section{Discussion}

Food allergy is an immunological reaction suffered by some individuals resulting from the consumption of certain foods and it involves IgE antibody which is responsible for a wide range of anaphylactic reactions. The IgE mediated hypersensitivity to foods causing allergic reactions such as asthma, rhinitis, atopic dermatitis, urticaria, oral symptoms such as swelling of lips and tongue, gastrointestinal disturbances or even anaphylaxis of varying degree are quite common. It is very difficult to identify a particular protein as allergenic and no particular secondary or tertiary structure can be described as solely and intrinsically allergenic. Particular foods such as black gram, lentil, Cajon pea, French beans, horse gram, mustard, radish, fruits and milk are found to be major allergenic foods in India. Cereals such as rice, wheat, rye, barley and oat have been reported to cause allergic reactions. Food additives such as caramine, tetrazine dyes used as food colors are known to cause food anaphylaxis. Anaphylactic reactions due to ingestion of caramine containing food such as yogurt, compare have also been identified [2]. Individuals are more likely to encounter difficulties when eating away from home [5].

In Ayurveda, allergic conditions are explained separately as independent entities such as Sheetapitta, Udarda and Kotha. Various etiological factors like asaatmya ahara (uncongenial/ allergenic food), viruddha ahara (incompatible food combinations), dushi visha (poisonous/allergic in nature) etc; plays a major role in causation of allergic conditions/urticaria. Various forms of urticaria, angioedema etc allergic conditions can be correlated with Sheetapitta, Udarda and Kotha. Sheetapitta and Udarda both are used synonymously but with a slight difference. Sheetapitta is a vata predominant condition whereas Udarda is kapha predominant. Various shodhana (body purificatory) procedures, shamanaushadhi's (pacificatory medicines) which are having the properties like, ushna (hot), teekshna (quick), ama pachaka (digestants) and vatanulomana (causing downward movement of vata dosha) are useful for vata, kapha shamana (for pacifying vata and kapha dosha) and also for the management of Sheetapitta and Udarda [6]. In present case, Haridra khanda and Sanjeevani gutika (Figure 2) were used in the acute management of food induced anaphylactic reaction successfully.

Haridra khanda is indicated in the management of allergic skin conditions like Sheetapitta, udarda and kotha (urticaria). Haridra (Curcuma longa Linn), Haritaki (Terminalia chebula Retz), Amlaki (Emblica officinalis Gaertn), Vibhitaki (Terminalia bellirica Roxb), Shunthi (Zingiber officinale Rosc), Pippali (Piper longum Linn), Maricha (Piper nigrum Linn), Twak (Cinnamomum zeylanica Blume), Ela (Elettaria cardamomum Maton), Tamala patra (Cinnamomum tamala Nees \& Eberm), Vidanga (Embelia ribes Brum.f.), Sita (candy sugar), ghrita (clarified butter) and loha bhasma (Fe203) are the ingredients of Haridra khanda. All the drugs of Haridra khanda are having the properties to control the allergic conditions and improve vyadhi kshamatva (immuno modulatory). Encouraging results were found with Haridra khanda granules in pratishyaya (allergic rhinitis) according to the previous work [7].
Sanjivani Vati/Sanjeevani gutika is a poly herbal formulation containing ten ingredients; vidanga (Embelia ribes), shunthi (Zingiber officinalis), pippali (Piper longum), haritaki (Terminalia chebula), amlaki (Emblica officinalis), vibhitaki (Terminalia bellerica), vacha (Acorus calamus), guduchi (Tinosporia cordifolia), bhallataka (Semicarpus anacardium), and visha (Aconitum heterophyllum). Sanjivani Vati is mainly used in the treatment of ajirna (dyspepsia), gulma (abdominal lump), vishuchi (gastroenteritis), sarpa damsha (snakebite), and in diarrhoea. "Aama" (undigested food material or abnormal metabolite or allergen) is the byproduct of faulty metabolism. It is accumulation of endo toxins within the body. This "Aama" leads to blockage in channels and produce many diseases. Sanjivani Vati combats all these as it ignites the digestive fire and helps the body to just get rid of all the mid-way metabolites from the system. The recommended in dose of Sanjeevani vati is $125 \mathrm{mg}$ to $500 \mathrm{mg}$ three times a day. [8] Sanjeevani vati is an excellent sannipatahara (able to pacify the three dosha's i.e. vata, pitta and kapha) drug with special action on vata and kapha [9].

Both Haridra khanda and Sanjeevani gutika (Figure 2) were able to pacify the progression of anaphylactic reaction in present case successfully. Unfortunately there were no proved efficacious drugs in the management of anaphylactic reactions and patients are dependent on intravenous antihistamines and corticosteroids. It is very difficult to carry and to administer these intravenous medications at all places and also at all times. In present case, the patient doesn't know the exact allergenic food, so it is very difficult for him to restrict the diet. The social life of the patient also get restricted due to the food allergy (patient has stopped dining out due to fear of anaphylactic reactions by foods prepared at restaurants by using artificial coloring agents or preservatives). In present case, the patient used to get anaphylactic reactions to various food items (most of them are prepared complex mixture of foods consisting various ingredients and complex method of preparation); so it is very difficult to avoid the wide range of suspected foods.

No adverse effects were reported with Haridra khanda and Sanjeevani gutika by the patient. The patient got clinically meaningful improvement with these medicines when they were administered at the initial stages of anaphylactic reactions. Patient has not continued these medicines after getting discharged and he has developed similar anaphylactic reactions two times (managed successfully by Haridra khanda and Sanjeevani gutika every time). Ayurvedic treatment seems to be promising in the management of acute anaphylactic reactions induced by food when administered during initial stages without causing any adverse effects.

\section{Limitations of the Present Study}

In present case due to various reasons like non availability, non affordability, lack of specificity, not knowing offending allergen and reluctance of the patient, skin prick test and IgE testing were not conducted. The diagnosis is solely made on history and clinical findings. Assessment is solely based on relief in clinical condition and no objective parameters were used in the present study. Present study findings can't be generalized and further 
experimental and/or clinical studies with large sample are required to substantiate these findings.

\section{Conclusion}

Sanjeevani gutika and Haridra khanda at the initial or early stages of food induced anaphylactic reaction seems to be beneficial in preventing anaphylactic shock or further aggravation of condition. These Ayurvedic drugs seem to be promising in the emergency management of acute food induced allergic reactions.

\section{Acknowledgement}

None.

\section{Conflict of Interest}

None.

\section{References}

1. Sampson HA (200) Food anaphylaxis. Br Med Bull 56(4): 925-935.

2. Gangal SV, Malik BK (2003) Food Allergy-How Much of a Problem Really is this in India? J Sci Ind Res 62 (08): 755-765.

3. Robison RG (2014) Food allergy: Diagnosis, management \& emerging therapies. Indian J Med Res. 139(6): 805-813.
4. Kshama Gupta, Prasad Mamidi (2016) Ayurvedic management of chronic idiopathic urticaria: A case report. J Pharm Sci Innov 5(4): 141-143.

5. Common LAR, Corrigan CJ, Smith H, Bailey S, Harris S, et al. (2013) How Safe is your Curry? Food Allergy Awareness of Restaurant Staff. J Allergy Ther 4(4): 140.

6. Prasad Mamidi, Kshama Gupta (2017) Ayurvedic management of Dermatographism. Indian Journal of Ancient Medicine and Yoga 10(1): 33-35.

7. Chaudhari VM, Manjusha R, Dhiman KS, Harish CR, Shukla VJ (2011) A preliminary pharmacognostical and physico chemical assay of haridra khanda granules: A pilot study. Int. J. Res. Ayurveda Pharm 2(6): 1681-1684.

8. Gairola S, Gupta V, Bansal P, Maithani M, Krishna CM (2010) Pharmacological activities of polyherbal formulation: Sanjivani vati. International Journal of Ayurvedic Medicine 2(1): 1-19.

9. Dilip V, Parul G, Kumar SA, Prakash SO (2011) Sanjeevani vati in Ayurvedic therapeutics with special reference to samprapti bhang. Int J Res Ayurveda Pharm 2(6): 1642-1644. 